\title{
Genome Mapping to Enhance Efficient Marker-Assisted Selection and Breeding of the Oil Palm (Elaeis guineensis Jacq.)
}

\author{
Essubalew Getachew Seyum ${ }^{1,2,3^{*}}$, Ngalle Hermine Bille1, Wosene Gebreselassie Abtew ${ }^{3}$, \\ Godswill Ntsomboh-Ntsefong1,4, Joseph Martin Bell1
}

${ }^{1}$ Department of Plant Biology and Physiology, Faculty of Sciences, University of Yaounde I, Yaounde, Cameroon ${ }^{2}$ CETIC (African Center of Excellence in Information and Communication Technologies), University of Yaounde I, Yaounde, Cameroon

${ }^{3}$ Department of Horticulture and Plant Sciences, Jimma University College of Agriculture and Veterinary Medicine, Jimma, Ethiopia

${ }^{4}$ Institute of Agricultural Research for Development, Yaounde, Cameroon

Email: ^g.essu2011@gmail.com, ^getachew.essubalew@cirad.fr, hbille2014@gmail.com, wosish@yahoo.com, ntsomboh@yahoo.fr, josmarbell@yahoo.fr

How to cite this paper: Seyum, E.G., Bille, N.H., Abtew, W.G., Ntsomboh-Ntsefong, G. and Bell, J.M. (2021) Genome Mapping to Enhance Efficient Marker-Assisted Selection and Breeding of the Oil Palm (Elaeis guineensis Jacq.). Advances in Bioscience and Biotechnology, 12, 407-425. https://doi.org/10.4236/abb.2021.1212026

Received: September 29, 2021

Accepted: December 10, 2021

Published: December 13, 2021

Copyright $\odot 2021$ by author(s) and Scientific Research Publishing Inc. This work is licensed under the Creative Commons Attribution International License (CC BY 4.0).

http://creativecommons.org/licenses/by/4.0/ (c) (i) Open Access

\begin{abstract}
The oil palm (Elaeis guineensis Jacq.) is one of the major cultivated crops among the economically important palm species. It is cultivated mainly for its edible oil. For a perennial crop like oil palm, the use of Marker Assisted Selection (MAS) techniques helps to reduce the breeding cycle and improve the economic products. Genetic and physical maps are important for sequencing experiments since they show the exact positions of genes and other distinctive features in the chromosomal DNA. This review focuses on the role of genome mapping in oil palm breeding. It assesses the role of genome mapping in oil palm breeding and discusses the major factors affecting such mapping. Generating a high-density map governed by several factors, for instance, marker type, marker density, number of mapped population, and software used are the major issues treated. The general conclusion is that genome mapping is pivotal in the construction of a genetic linkage map. It helps to detect QTL and identify genes that control quantitative traits in oil palm. In perspective, the use of high-density molecular markers with a large number of markers, a large number mapping population, and up-to-date software is necessary for oil palm genome mapping.
\end{abstract}

\section{Keywords}

Genome Mapping, Crop Improvement, Marker Assisted Selection, 
Oil Palm, Biotechnology

\section{Introduction}

The oil palm (Elaeis guineensis Jacq., Arecaceae) originated from West Africa [1] [2]. It is a diploid $(2 n=2 x=32)$, perennial monocot plant, and the most productive oil-producing crop in the world. It is mainly cultivated in humid tropical zones of the world [3] [4]. It is naturally cross-pollinated, monoecious, and allogamous. The economic life span of the oil palm is about 30 years [5] [6].

According to the United States Department of Agriculture (USDA) [7], the total world vegetable oil production as of 2020/2021 was 72,769 MT, led by soybean oil (362.64 MT), followed by palm oil (75.19 MT), and rapeseed oil (69.17 MT) and sunflower seed (49.66 MT). Oil palm produces on average 4 metric tons of oil per hectare every year [8] [9]; this is approximately 10 times higher than soybean. Palm oil falls into two major applications: the food industry (with over $80 \%$ of the market) and the rest for the chemical industry for formulation of paints, inks, resins, varnishes, plasticizers, biodiesel production, etc. [3] [10].

Despite its wide adaptation and importance, oil palm production and productivity are generally far from their potential due to several biotic and abiotic constraints. Climate change, land, and a labor shortage are major factors that hinder yield and palm oil quality across the world [11]. Moreover, breeding of oil palm is made difficult because of the perennial nature of the crop that limits the rate of increasing palm oil yield and quality. Equally, Herrero et al. [12] reported that breeding of oil palm is applicable through the use of the conventional method, which needs more space and time for selecting promising crosses, mainly when increasing parental biodiversity. To alleviate this problem and improve oil palm yield and quality, breeders need to implement molecular techniques of oil palm breeding.

In marker-assisted selection (MAS), the use of a molecular marker with quantitative trait loci (QTL) helps in phenotypic screening to address the limitations of traditional breeding methods. The accuracy and efficiency of selection are improved by MAS [13]. The method brings a remarkable result mainly for traits with low to moderate heritability, which is difficult to achieve by the traditional breeding method. In most cases, MAS breeding requires knowledge about the distribution of QTL for the targeted trait inside the genome. In many crop species including the oil palm, MAS has been instrumental in the genetic improvement of several agronomic traits [13]. In oil palm, the use of MAS studies has been discussed since the 1990s [14]. In whole genome sequencing research, linkage maps, molecular markers, and QTL maps are crucial for MAS. In several crop species, linkage maps, a large number of DNA markers, and identification of QTL for major traits have been developed [15].

Genetic linkage maps express the actual inheritance of loci into offspring based on the patterns of recombination during meiosis [16]. In the oil palm, different genetic linkage maps from numerous families of oil palm have been constructed with remarkable results based on MAS breeding studies. Some genetic 
maps have been constructed for the oil palm using amplified fragment length polymorphism (AFLP) [17] [18], restriction fragment length polymorphism (RFLP) [14] [18], random amplified polymorphic DNA (RAPD) [19], simple sequence repeats (SSR) [20] [21] [22] [23], and single nucleotide polymorphism (SNP) [12] [24] [25] [26] [27]. Still, with the oil palm, numerous quantitative trait loci (QTL) mapping reports have revealed the existence of major-effect QTLs for many traits [12] [15] [18] [19] [20] [23] [27] [28] [29] [30]. The objective of this review was to assess and highlight the role of genome mapping in oil palm breeding and discuss the major factors affecting genome mapping.

\section{Types of Genome Maps}

Several types of maps exist such as cytogenetic map, physical map, and genetic map.

\subsection{Cytogenetic Map}

This is the visual appearance of a chromosome when stained and/or labeled under a microscope [31] [32]. The units for the cytogenetic map are a fraction of a chromosomal arm or centiMcClintocks (cMc) (Figure 1) [33]. This is obtained by visualizing distinct regions marked by light and dark bands which give each of the chromosomes a unique appearance. The map shows the positions of chromosomes in the bands, i.e. bandmap (genome deletion panel) [33] [34]. Hozier and Davis [35] showed that the integration of this method of mapping with other molecular genetic mapping methods allows the study and mapping of different mammalian genomes. Azhaguvel et al. [36] reported that this type of map is the earliest that has been used for mapping fruit fly and the corn crop. Shah [34] on their part showed that the application of the cytogenetic mapping method is advantageous to study genome analysis, chromosome mapping, and analysis of somaclonal variations in tissue culture.

\subsection{Physical Map}

Physical mapping reflects the actual physical distance in base pairs (bp) or multiples thereof (for example, kilobases $(\mathrm{kb})$ i.e. $\mathrm{bp} \times 1000$ ) between molecular markers (Figure 1) [37] [38]. Such maps are increasingly being used to understand the molecular insights of genes and their evolution [36]. According to O'Rourke [16], physical maps provide an effective tool to isolate and study genes: where they are, what they do, and how they interrelate? A better understanding of these maps allows the location of the marker in the chromosome with the centromere and telomeres and permits the detection of some mutation phenomena such as insertions, deletions, and translocations [39]. Due to the current advancement in sequence technology, there is a constant increase of interest in these maps mainly because of the difficulty of assembling large fractionated genomes without a good physical map [40]. Dixit [33] stated that, unlike genetic maps, the construction of a physical map requires molecular biology techniques; indeed, it represents the entire genome as a set of overlaying cloned 


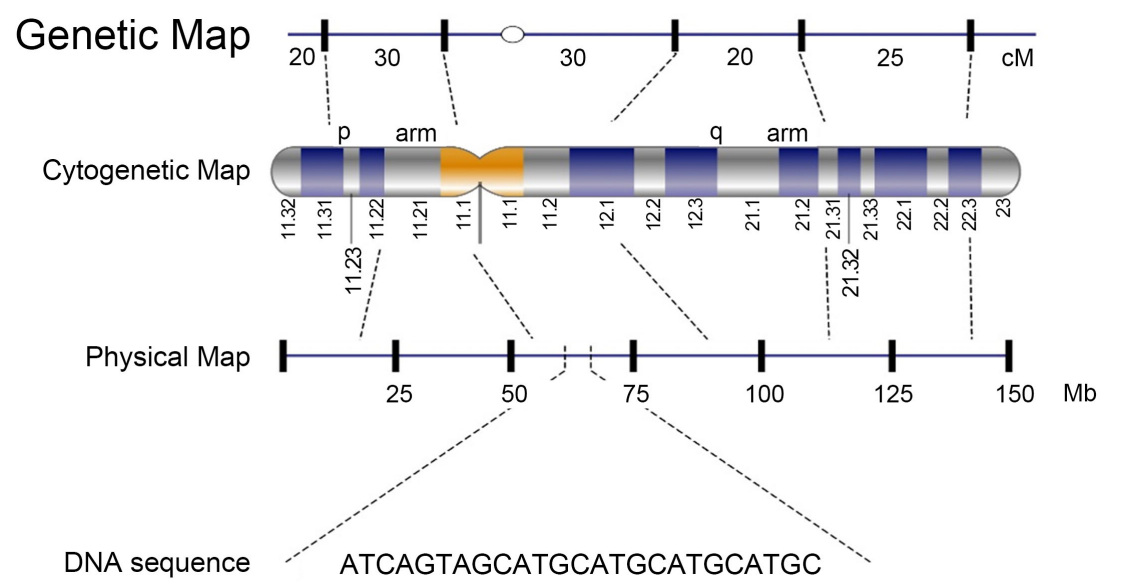

Figure 1. Illustration of physical, genetic map, and position of markers in the chromosome.

DNA fragments that make up a genome and this is ordered with respect to a reference map (such as a genetic map). In the same light, Deonier [38] reported the usefulness of the construction of wide-ranging physical maps for studying the characteristics of both sequenced and unsequenced genomes. These maps are used in the genomic study of oil palm, in addition to genetic maps. For instance, Herrero et al. [12] reported that this map can be used for the analysis of quantitative trait locus for the traits of interest, generally for crop and specifically oil palm breeding.

\subsection{Genetic Map}

Genetic maps show the positions of genes and other related sequence features like DNA markers in the genome, based on how often the genes or markers are inherited together [31] [32] [37]. It shows the map distance, in cM, which separates any two loci, and the position of these loci relative to all other mapped loci (Figure 1) [41]. It is constructed based on the meiotic recombination between homologous chromosomes [36]. The use of high-resolution genetic maps is very pertinent since they determine the relationship between breeding and genome sequencing. Likewise, O'Rourke [16] outlined that in the genetic and genomic studies of plants or animals, the application of high-density genetic maps full of polymorphic markers is a key for marker-assisted selection. Conversely, Li [42] noted that the construction of high-density and high-resolution genetic maps is vital to the structural and functional understanding of the genome and genes of interest through linkage analysis. Dixit [33] showed that a high resolution of the genetic map is determined by several factors such as the number of crossovers in a plant species that have been scored or a large number of progeny in humans. They also stated that the type of molecular markers used also has an impact on the resolution of the map.

\section{Genetic vs. Physical Maps}

Genetic and physical maps demonstrate the arrangement of genes and DNA 
markers on a chromosome, respectively. Details of their differences are presented in Table 1. The genetic map is also known as a linkage map. It describes genes or loci within a chromosome based on recombination rate [36]. This mapping concept was first developed by Sturtevant [43], established by linearly placing five sex-linked genes on the Y chromosome of fruit fly (Drosophila melanogaster). It provides an approximate distance between loci in the genome in terms of recombination rate and its determination is based on the number of crossovers [33]. O'Rourke [16] showed that crossing over frequency between genes or DNA markers is proportional to the chromosomal distance between them. For instance, the more closer the genes, the fewer crossover frequencies, and vice-versa. It allows the establishment of linkage associations between genes or DNA markers and it is a baseline to establish the physical mapping, thereby opening a door for map-based genome isolation. This map does not allow the study of particular chromosomes in the genome, rather a set of polymorphic genetic marker loci or genes [36]. In this map, the genetic distance between two molecular markers is computed based on the number of recombination events without precision on the actual physical distance [33]. To address the above problem, physical mapping has to be performed.

A physical map has a linearly ordered set of molecular markers (DNA fragments) surrounding the whole genome or a particular genomic region of interest [31] [32]. Azhaguvel [36] classified this map into two types. The first is the macro-restriction map which gives information regarding the DNA fragments at the chromosome level. The second is known as the ordered clone map consisting of an overlapping collection of cloned DNA fragments, such as in yeast and bacterial artificial chromosome (YAC). It determines the actual distance of DNA markers on the chromosomes in base pairs [33]. The genetic-physical map ratio varies significantly from one chromosome region to the other. It is mainly dependent on the nature of the chromosome and the frequency of recombination in that region [36]. For example, the estimated genetic to physical distance ratio of oil palm range from $68.44 \mathrm{Mb} / \mathrm{cM}$ to $21.37 \mathrm{Mb} / \mathrm{cM}$ [25].

Table 1. Differences between genetic and physical maps.

Genetic map $\quad$ Physical map

It is the calculated map distance based on the crossover percent between two linked genes

The actual physical distance between linked genes

This map distance highly varies as the frequency of crossing The physical distance of linked genes bears no direct over varies in a different segment of chromosomes and it is only a relationship to the map distance calculated based on crossover predicted value percentages

The distance measured in Map unit or centiMorgan

The distance measured in base pairs (bp, Kbp, Mbp)

Linear order is identical as in the physical map

Linear order is identical as in the genetic map

The relative distance between two genes

The exact location of genes in the chromosomes 
The need for physical-genetic maps has increased steadily in the past decade. Since then these two maps are used fully to study gene cloning and whole-genome and specific genome region DNA sequencing [31] [32]. A genetic map constructed to identify the target gene and closely linked DNA markers were used to filter a large set of the library used to construct the physical map [36]. Then, the newly produced DNA markers were used to identify the clones for genetic fine mapping. O'Rourke [16] reviewed the correlation of genetic and physical maps and revealed that physical maps consist of ordered library pieces of DNA covering entire genomes or chromosomes; the genetic map was constructed based on the recombination analysis of molecular markers, with the main target to identify the cloning genes. Physical and genetic map integration is used to identify the genomic region that has a high recombination hot spot region with repressed recombination [44]. Azhaguvel [36] noted that such integration reveals all about the genome sequences. This opens a new door to develop DNA markers, identify genes, quantitative trait loci (QTLs), expressed sequence tags (ESTs), regulatory sequences, and repeat elements.

\section{A Molecular Marker Used for Mapping in Oil Palm Populations}

Molecular markers are widely used nowadays in various plant breeding programs to track loci and genomic regions [36]. Identification of major genes controlling quantitative traits in crop plant genomes is possible with molecular markers. To this end, genetic mapping techniques are used to retrieve and locate important genes and genomic information responsible for a particular trait [31] [32]. Several genetic maps have been established for a wide range of plant species using various molecular marker systems such as RFLP [45], RAPD [46], simple sequence repeat (SSR), or microsatellite [47], sequence-tagged sites (STS) [48], AFLP [49], single-nucleotide polymorphism (SNP) [50], sequence-characterized amplified region (SCAR) [51], and cleaved amplified polymorphic sequences (CAPS) [52]. Depending on different purposes for gene mapping, each of the molecular markers has its pros and cons (Table 2). However, RFLP, RAPD, SSR, and AFLP markers are most commonly used in plant species for genetic mapping [16].

In the oil palm, different molecular marker types have been used for the construction of genetic linkage maps (Table 3). They include RFLPs [14] [18] [29] [30], RAPDs [19], AFLPs [18] [19] [22] [23] [30], SSRs [3] [15] [18] [19] [20] [21] [23] [30] [53] [54] [55], and SNPs [12] [15] [24] [25] [26] [27] [28] [53] [54] [55]. In this paper and for the first time, we review the primary results of oil palm genome mapping as summarized in Table 3 . This table shows an outline of the major studies on oil palm genome mapping with their different features.

\section{Oil Palm Genome Mapping}

Genetic linkage maps reflect the actual inheritance of loci from parents to their offspring based on the patterns of recombination during meiosis. In oil palm for 
Table 2. Evaluation of the most widely used molecular marker systems.

\begin{tabular}{|c|c|c|c|c|c|c|}
\hline Marker Name & PCR-based & Polymorphism (abundance) & Dominance & Reproducibility & Automation & Running cost \\
\hline RFLP & No & Low/medium & Codominant & High & Low & High \\
\hline RAPD & Yes & Medium/high & Dominant & Low & Medium & Low \\
\hline SCARS/CAPS & Yes & High & Codominant & High & Medium & Medium \\
\hline AFLP & Yes & High & Dominant & High & Medium/high & Medium \\
\hline SSR & Yes & High & Codominant & High & Medium/high & Low \\
\hline ISSR & Yes & High & Dominant & High & Medium/high & Low \\
\hline STS & Yes & High & $\begin{array}{c}\text { Codominant/ } \\
\text { dominant }\end{array}$ & High & Medium/high & Low \\
\hline SRAP/EST & Yes & Medium & Codominant & High & Medium & Low \\
\hline IRAP/REMAP & Yes & High & Codominant & High & Medium/high & Low \\
\hline SNP & Yes & Extremely high & $\begin{array}{c}\text { Codominant/ } \\
\text { dominant }\end{array}$ & High & High & Low \\
\hline
\end{tabular}

Table 3. Summary of linkage map constructed in oil palm.

\begin{tabular}{|c|c|c|c|c|c|c|c|}
\hline No. & Year & Type of markers & No of Markers & Map depth (cM) & No of LGs & Software use to construct LGs & References \\
\hline 1 & 1997 & RFLP & 97 & 860 & 24 & MAPMAKER 2.0 & {$[14]$} \\
\hline 2 & 2000 & RAPD & 48 & $399.7-449.3$ & $12-15$ & MAPMAKER 2.0 & [19] \\
\hline 3 & 2001 & RFLP & 153 & 852 & 22 & JoinMap 2.0 & [29] \\
\hline 4 & 2005 & MS and AFLP & $255+688$ & 1743 & 16 & JoinMap ver. 3.0 & [17] \\
\hline 5 & 2009 & AFLP, RFLP, MS & 252 & 1815 & 21 & Joinmap ver. 4.0 . & {$[18]$} \\
\hline 6 & 2010 & SSR & 251 & 1479 & 16 & JoinMap v. 3.0 & {$[20]$} \\
\hline 7 & 2011 & AFLP & 331 & 2274.5 & 16 & MAPRF7 & {$[22]$} \\
\hline 8 & 2013 & AFLP, RFLP, SSR & 148 & 798.0 & 23 & JoinMap 4.0 & {$[30]$} \\
\hline 9 & 2013 & SSR & 362 & 1845.0 & 16 & JoinMap v.4.0 & [3] \\
\hline 10 & 2014 & SSR, Genes, SNP & 190 & 1233.0 & 31 & JoinMap v.4.0 & [54] \\
\hline 11 & 2014 & SSR, AFLP & 423 & 1931 & 16 & JoinMap v 3.0 & {$[23]$} \\
\hline 12 & 2014 & SSR, SNP & 1331 & 1867 & 16 & JoinMap v 4.1 & {$[55]$} \\
\hline 13 & 2015 & SSR, SNP & 480 & 1565.6 & 16 & JoinMap v 3.0 & {$[15]$} \\
\hline 14 & 2015 & SNP & 1085 & 1429.6 & 16 & JoinMap v 3.0 & [27] \\
\hline 15 & 2015 & SSR & 281 & 1935.0 & 16 & CRIMAP & {$[21]$} \\
\hline 16 & 2018 & SNP, SSR & 10,023 & 2398.2 & 16 & Lep-MAP v 2 & [53] \\
\hline 17 & 2018 & SNP, DArTseq & $1399-1466$ & $1873.7-1720.6$ & 16 & JoinMap v 4.1 & {$[24]$} \\
\hline 18 & 2018 & SNP & 2413 & 1161.89 & 16 & JoinMap v 4.1 & [28] \\
\hline 19 & 2019 & SNPs & 27,890 & 1151.7 & 16 & Lep-MAP3 & {$[25]$} \\
\hline 20 & 2020 & SPET & 3501 & 1,370 & 16 & Lep-MAP3 & {$[12]$} \\
\hline 21 & 2020 & SNPs & 11,421 & $1151.70-1268.26$ & $17-24$ & Lep-MAP3 & [26] \\
\hline 22. & 2022 & SNPs & - & - & 16 & Lep-MAP3 & $\begin{array}{c}\text { Essubalew } \\
\text { et al. } 2022 \\
\text { (under } \\
\text { review) }\end{array}$ \\
\hline
\end{tabular}


the last 20 years, several linkage maps have been constructed and used to detect different vegetative, yield, and yield components and palm oil quality traits [25]. In the same light, markers like RFLPs, AFLPs, SSRs, and SNPs are widely used to construct genetic linkage maps in oil palm. Recently, restriction associated DNA tagging (RAD), double digestion RAD (ddRAD), single primer enrichment technology (SPET) have been recognized for producing a large number of SNPs with remarkable maps [12].

In oil palm, the first genetic linkage map constructed based on RFLP markers from genomic libraries was published in 1997. This map which considers 97 RFLP markers (84 probes) mapped a selfed guineensis cross (tenera $x$ tenera) with a total genetic distance of $860 \mathrm{cM}$, and produced a total of 24 linkage groups using a LOD score of 4 and recombination fraction of 0.4 . According to the study [14], more than $95 \%$ of the markers could be linked to at least one other marker, suggesting that good genome coverage helps to detect the position of the shell thickness gene $(S h)$ at a distance of $9.8 \mathrm{cM}$ on group 10. From their result, Mayes et al. [14] concluded that this map helps to enable the mapping of the gene responsible for controlling major commercial oil palm traits. Likewise, Rance [29] also used 153 RFLP markers to construct a genetic linkage map of 84 self-fertilization F2 oil palm populations used to detect major genes influencing shell thickness. The result confirms that QTL mapping helps to detect genes that influence a large proportion of the total phenotypic variance in a large and small population.

Further, RAPD is another marker used to construct a genetic linkage map in the oil palm. The first RAPD marker map was developed by Moretzsohn [19] to develop a pseudo-testcross mapping strategy in combination with the RAPD assay. This was meant to construct genetic linkage maps of different fruit types (shell thickness) of $\mathrm{F}_{1}$ tenera ( $\left.s h+s h-\right) \mathrm{x}$ pisifera ( $\left.s h-s h-\right)$ progeny populations. The map used a total of 48 RAPD markers, and $308 \mathrm{~F} 1$ progeny populations, and produced a total of 12 linkage groups with a map distance ranging from 399.7 $449.3 \mathrm{cM}$ at a LOD score of 5.0 and by considering the projected Elaeis total map distances and genome sizes, physical and genetic distances relationships were established (1.06 Mbp/1 cM and 1.09 Mbp/1 cM, for tenera and pisifera, respectively). They also obtained limited genome coverage with the two maps (28.0\%, for tenera and $25.6 \%$, for pisifera). This result depicted the importance of RAPD markers used for genetic linkage mapping markers closer to the $s h+$ locus, helped to detect the gene responsible for shell thickness, and gave a step forward for MAS for shell thickness in the oil palm.

AFLP is another pronounced marker used to construct a genetic linkage map in the oil palm. The first AFLP based genetic map in oil palm was developed by Billotte et al. [17] involving a cross between a thin-shelled E. guineensis (tenera) palm and a thick-shelled E. guineensis (dura) palm with the main goal of mapping to detect the presence and absence of the gene responsible for shell in the oil palm fruit. For this purpose, they used a total of 944 (255 SSRs, 688 AFLPs, 
allele $S h^{-}$) markers with a map length of $1743 \mathrm{cM}$ and with an average of one marker every $1.8 \mathrm{cM}$ and LOD score 3.0, producing a total of 16 linkage groups. The lengths of the linkage groups varied between $59 \mathrm{cM}$ and $192 \mathrm{cM}$. This map was the first linkage map for the oil palm to have 16 independent linkage groups corresponding to the haploid chromosome number of 16 in the oil palm. Their findings on high-density linkage maps could step forward research for QTLs and physical mapping in the E. guineensis species. Besides, they also reported that SSRs marker had better mapping resolution compared to that of AFLPs. This is because high-density markers like SSRs have higher recombination rates than low-density markers like AFLPs. From the result, they observed that SSRs markers are well distributed along the genome than AFLPs markers. Conversely, Singh [18] reported an interspecific cross involving Colombian Elaeis oleifera (UP1026) and a Nigerian E. guinneensis (T128) and a total of 118 palms from this interspecific cross were used to detect quantitative trait loci (QTLs) controlling oil quality (measured in terms of iodine value and fatty acid composition). To analyze the map, they used a total of 252 markers (199 AFLP, 38 RFLP, and 15 SSR) with a map length of $1815 \mathrm{cM}$ and with an average interval of $7 \mathrm{cM}$ between adjacent markers, producing a total of 21 linkage groups with an average number of 12 markers per linkage groups. Again, almost in all maps, the markers were distributed at an interval of $25 \mathrm{cM}$ except for linkage group 17 having $30 \mathrm{cM}$, indicating that the map is relatively homogeneous with regards to marker distribution; this is useful for tagging traits of economic interest for MAS. In this map, the length of individual linkage groups varied from $26.1 \mathrm{cM}$ to $168 \mathrm{cM}$, with an average of $94 \mathrm{cM}$. The application of the genetic linkage map helps to detect QTLs for fatty acid composition in oil palm and serves as a tool for the MAS breeding program.

Similarly, a report from Seng [22] used a total of 120 hybrid crosses between high-yielding dura (ARK86D) x pisifera (ML161P) using AFLP markers. To construct the map, they used a total of 479 marker loci and 168 anchor points with a map length of $2247.5 \mathrm{cM}$ and an average map density of $4.7 \mathrm{cM}$ using LOD score of 3.0. They constructed a total of 16 linkage groups from 15-57 markers per linkage group with an average of 29 markers per linkage group and with the lengths ranging from $77.5 \mathrm{cM}$ to $223.7 \mathrm{cM}$, and an average of $137 \mathrm{cM}$. In line with this, the markers were well distributed all over the 16 linkage groups. From their findings, Seng [22] concluded that the application of a genomic map in oil palm helps to validate against a closely related population and helps identify yield-related QTLs. Likewise, Ting et al. [30] and Ukoskit [23] also used the AFLP markers to construct a genetic linkage map in oil palm.

Simple sequence repeat (SSR) markers are co-dominant molecular markers that distinguish polymorphism and mapping in the oil palm genome. SSR markers were used for the first time to construct the map of the oil palm in the year 2005 . To construct the map, Billotte et al. [17] used a total of 255 SSR markers with a map length of $1743 \mathrm{cM}$ with an average marker density of $7 \mathrm{cM}$. using a LOD 
score of 3.0 and producing a total of 16 linkage groups. Based on the outcome of their finding, mapping of oil palm using high-density makers like SSR brings comprehensive information for QTL mapping and other MAS research in the oil palm. In line with this, Billotte [20] used an SSR marker for QTL detection with a multi-parent linkage map of the cross between two oil palm populations. They used a total of 150 palms in the controlled cross between Africa (LM2T) x Deli (DA10D). To construct the map, a total of 251 SSR markers were used. Based on their finding, the SSR map for LM2T x DA10D had 16 linkage groups (LGs) and 253 loci, with a map length of $1479 \mathrm{cM}$ and an average marker density of $6 \mathrm{cM}$. The large mapping genome was found in LG4 with spanned $134 \mathrm{cM}$ on the average range of $61-250 \mathrm{cM}$ and around $47 \%$ of the mapped loci having three or four alleles with an average density of $32 \mathrm{cM}$ on the genome. In conclusion, a total of 156 SSRs (45\%) and the Sh locus were mapped and the mapping of the crossed oil palm populations helped to identify the QTL for the major gene controlling fruit shell (Sh). By the same token, Montoya et al. [3] used a total of 347 segregating SSRs, 14 SNPs of genes, and the $S h$ locus to establish the linkage map and to detect QTLs of palm oil fatty acid composition. They produced a total of 16 LGs with a relative map length of $1485 \mathrm{cM}$ and an average marker density of 4 cM at LOD 7.5 with a maximum recombination threshold of 0.3 . Depending on their position on the linkage group, the length of the LGs ranged from 49.1 to $175.9 \mathrm{cM}$, with an average of $92.8 \mathrm{cM}$. Concerning QTLs, a total of 19 QTL associated with the palm oil fatty acid composition was obtained and this mapping helped to identify key genes in the oil palm genome related to oleic acid C18:1. In conclusion, $73 \%$ (253) of the mapped SSRs segregated only from the hybrid parent SA65T, 2\%, (7) from PO3228D only, and 27\% (93) were common SSRs segregating from both parents. Again, the high number of mapped SSR loci with accurate relative linear orders, and their molecular hyper-variability helped to undertake other such mapping studies in other Elaeis breeding materials. Later on, Cochard [21] constructed a linkage map using a 281 SSRs marker and a total of 271 genotyped oil palm populations. They produced a total of 16 linkage groups covering group A $(2078 \mathrm{cM})$ and group B $(1845 \mathrm{cM})$, with an average density of one marker every 9 and $7 \mathrm{cM}$, respectively. Generally, the integrated maps gave a total map length of $1935 \mathrm{cM}$ with a total of 281 markers and an average density of one marker for every $7.4 \mathrm{cM}$. Besides, the marker orders between physical and genetic maps were in good accordance, except for some sporadic markers. Based upon their finding they concluded that this output could help to step towards efficient pedigree-based quantitative trait locus (QTL) mapping using the first intercrossed generations in current breeding programs. Similar studies have been done using SSRs for the mapping of the oil palm genome. For instance, QTLs identification is associated with callogenesis and embryogenesis [30], QTL mapping for oil yield using African oil palm [54], linkage map and QTL analysis for sex ratio and related traits [23], genetic map construction for two independent oil palm hybrids [55], linkage mapping and identifica- 
tion of major QTL genes for stem height [15] which all brought remarkable information for the oil palm genome mapping and molecular breeding research.

Currently, oil palm single nucleotide polymorphisms (SNPs) are the most highly preferred and high-density markers used to study genetic diversity and population structure, to construct high-density genetic maps, and provide genotypes for the genome-wide association [56], and genomic selection studies [5]. The first SNP marker-based oil palm genome mapping was constructed by Jeennor and Volkaert [54] using a total of 190 segregating loci (89 SSRs, 90 genes, and 11 non-gene based SNP markers), which were mapped into 31 linkage groups by applying threshold LOD of 3 and a recombination fraction of 0.45 . They produced a map with a total length of $1233 \mathrm{cM}$ containing two to 20 markers covering a length between 1.5 and $103.5 \mathrm{cM}$, and with an average distance between markers of $6.5 \mathrm{cM}$. This finding helped to identify validated candidate genes involved in lipid biosynthesis and mapped near significant QTL for various economic yield traits. This indicates the applicability of markers for MAS to improve the required trait selection for the oil palm breeding programs.

Moreover, Pootakham [27] developed SNP markers using the GBS method in the African oil palm with a total of 1085 SNPs to construct a linkage map. The map produced spanned $1429.6 \mathrm{cM}$ and had an average of one marker every 1.26 cM. They also detected on LG 10, 14, and 15, three QTL genes affecting trunk height whereas a single QTL associated with fruit bunch weight was identified on LG 3. They concluded that mapping of oil palm genome by the use of Genotyping by sequencing (GBS) approach helped to produce high-density maps and could enhance knowledge on genome structure which is valuable for mapping other economically important genes for MAS. Bai et al. [28] also used high-density GBS marker data to construct and detect QTL associated with leaf area using 145 oil palm breeding populations derived from a cross between Deli Dura and Avros Pisifera. They constructed a genetic linkage map using a total of 2413 SNPs, producing a total of 16 linkage groups with a total length of $1161.89 \mathrm{cM}$, and an average marker spacing of $0.48 \mathrm{cM}$. Based on their results, two potential QTL for leaf area were detected on Chr 3 and 9 and the gene ARC5, located in the QTL region on $\mathrm{Chr}$, was the most likely candidate gene responsible for leaf growth in oil palm. They concluded that the use of a high-quality and SNP-based map supplies a base to fine map QTL for agronomic traits and MAS yield improvement in oil palm.

Furthermore, Gan [24] reported the first DArT-based genetic linkage maps using two closely related oil palm populations. For this purpose, they used a total of 1399 DArT and 1466 SNP markers. They produced a total of 16 major independent linkage groups with map lengths of 1873.7 and $1720.6 \mathrm{cM}$ and with an average marker density of 1.34 and $1.17 \mathrm{cM}$, respectively. The integrated map was $1803.1 \mathrm{cM}$ long with 2066 mapped markers and an average marker density of $0.87 \mathrm{cM}$. In conclusion, the use of high-density marker DArTseq marker 
helped to generate high-density genetic maps in oil palm, and the integration of maps was also useful to study QTL analysis of important yield traits and other MAS studies. By the same token, Ong [25] also reported a linkage-based genome assembly in oil palm. To construct the map, they used a total of 27,890 SNP markers and generated a total of 16 linkage groups with a total map length of $1151.7 \mathrm{cM}$ and an average mapping interval of $0.04 \mathrm{cM}$. This mapping helped to study QTLs in sugar and lipid biosynthesis pathways. It also helped to improve knowledge on the current physical genome of the commercial oil palm.

Recently, Single Primer Enrichment Technology (SPET) markers were used to construct a high-density genetic linkage map from a controlled cross of two oil palm (Elaeis guineensis) genotypes [12]. To construct the map, they used a total of 3501 SPET markers with a total length of $1370 \mathrm{cM}$ and 1.74 markers per $\mathrm{cM}$ $(0.57 \mathrm{cM} /$ marker). This resulted in a total of 16 linkage groups with a total of 1054 loci. From their work, they concluded that the application of these cost-efficient SPET markers are suitable for linkage map construction in oil palm and probably, also in other species.

\section{Factors Limiting Oil Palm Genome Mapping}

For the last two decades, numerous findings in the area of oil palm genome mapping have been reported by different scholars (Table 3 ). These have remarkably improved knowledge on the genetic improvement of the oil palm using marker-assisted selection strategies. However, the success of genome mapping of the oil palm is highly dependent on several factors. For instance, Mayes et al. [14] reported that the choice of mapping populations is one of the major determinant factors of genome mapping of the oil palm, stating that to select them, several criteria were to be considered such as the simplicity of cross for allele scoring and linkage analysis, representation of alleles within breeding materials, and availability of phenotypic data. The variation is very clear between Asian and African types of oil palm genetic materials. Again, another factor affecting genome mapping is the genetic marker type used for mapping. In this regard, a report (Table 3), clearly showed that marker polymorphism creates a variation in the outcome of genetic linkage groups. For instance, the first RFLP marker by Mayes et al. [14] produced a total of 24 LGs, while the first SSR marker by Billotte et al. [17] produced 16 LGs. Very recently, the use of high-density markers like SNPs brought more light to the genetic mapping of oil palm. In addition to the type of marker, the density of markers used also brought variation in genome mapping of the oil palm. For example, Mayes et al. [14] used a total of 97 RFLP markers while Rance [29] used a total of 153 RFLP markers. Moreover, a total of 49 additional marker loci resulted in an improvement of map resolution from 24 linkage groups [14] to 22 linkage groups [29] and not only the map resolution but, also the total map length differed; as the number of markers increased from 97 to 153, the map length decreased from $860 \mathrm{cM}$ to $852 \mathrm{cM}$, respectively. Conversely, Billotte et al. [17] used a combination of 255 SSR and 688 
AFLP markers, based on this and due to the high-density markers used (AFLPs); $23 \%$ of the filled gaps were covered by this marker relative to the SSR based map. In the same vein, compared to the results of Billotte et al. [17] i.e., 255 SSRs in combination with other low-density markers resulting in a total length of 1743 $\mathrm{cM}$ with an average marker density of $7 \mathrm{cM}$, Billotte [20] recently used independent high-density markers i.e., 251 SSR and obtained a total map length of 1479 $\mathrm{cM}$ with an average marker density of $6 \mathrm{cM}$. The variation is clear that in the later, they used a single high-density mapping marker.

Besides, the population sample size is another factor that brings a variation in the genome mapping of the oil palm. Singh [18] reported that even though they are using high numbers of markers, this doesn't result in a fine map. Based on their conclusion, this result is due to the use of a small sample size of the F1 progeny. Equally, Billotte [20] reported that there is a variation of map detection power, due to the variation in population size, and based on their report, a large population size of the multi-parent system provides greater detection power for the QTL than biparental and small populations. By the same token, Ukoskit [23] also reported that the difference in map length is due to the variation in the population size. In general, a large number of markers with large population sizes (pedigree populations) results in better genome mapping [57].

Last but not the least, genome mapping is also highly governed by the software used for mapping the genome. In the oil palm, various software programs have been used to build genetic linkage maps (Table 3), such as MAPMAKER 2.0 [58], JoinMap ver 2.0 [59], CRI-MAP [58], JoinMap ver 3.0 [60], JoinMap ver 4.0 [61], Lep-MAP 2 [62] and LepMAP 3 [57]. Due to the perennial nature of the oil palm, its out-crossing nature and long generation time result in difficulty to obtain enough genetic materials or mapping populations, to overcome these limitations, consensus genetic maps are obtained by integrating multiple unrelated genetic maps sharing common markers. Such consensus maps can be constructed by different linkage map software (Table 3). Nowadays, Lep-MAP3 (LM3) is a novel linkage map construction software suite. It can handle millions of markers and thousands of individuals possibly from multiple families [57].

\section{Conclusion}

In perennial crops like oil palm, getting new or improved varieties through conventional breeding methods is difficult because it is time-consuming and costly, all related to the long generation cycles, large plant size, and the long evaluation period of 10 - 15 years. The application of marker-assisted breeding techniques in this crop helps to minimize the above-listed constraints. The construction of genetic linkage maps plays a major role in the genetic analysis and molecular breeding programs of oil palm. This has been used for the identification of genetic loci using different traits such as yield and its components, oil quality, and abiotic stress, resulting in better genetic improvement and more cost-effective breeding. Nowadays, high-throughput molecular markers sequencing technolo- 
gy helps to raise both genetic and physical maps to a new level by providing an increased sequence pool from which to build genetic maps and assemble genome sequences. In the last two decades, most of the research findings reveal that genome mapping helps in the identification of major genes that control quantitative traits like yield and quality of oil palm. Furthermore, the literature on this crop shows that there is a variation of genome mapping due to several factors; for instance, marker type, marker density, size of the mapped population, and software used. Despite all pros and cons, genome mapping in this crop plays a crucial role, and to get a more pronounced map in the future, oil palm genome mapping should focus on the use of high-density molecular marker types, a large number of mapping population, and up-to-date software that can yield remarkable results and help to map and detect more quantitative traits related to both yield and oil quality.

\section{Authors' Contributions}

Essubalew Getachew SEYUM: Developed an idea and wrote the manuscript whereas all others are involved by commenting, suggesting, and re-arranging the setup of the manuscript.

\section{Acknowledgements}

The authors acknowledge the GENES program of the Intra-Africa Academic Mobility Scheme of the European Union for financial support (EU-GENES: 20172552/001-001).

\section{Conflicts of Interest}

The authors declare no conflicts of interest regarding the publication of this paper.

\section{References}

[1] Cros, D., Denis, M., Bouvet, J.M. and Sánchez, L. (2015) Long-Term Genomic Selection for Heterosis without Dominance in Multiplicative Traits: Case Study of Bunch Production in Oil Palm. BMC Genomics, 16, Article No. 651. https://doi.org/10.1186/s12864-015-1866-9

[2] Hartley, C.W.S. (1988) The Oil Palm (Elaeis guineensis Jacq.). Longman Scientific \& Technical, New York.

[3] Montoya, C., Lopes, R., Flori, A., Cros, D., Cuellar, T., Summo, M., Espeout, S., Rivallan, R., Risterucci, A.M., Bittencourt, D., Zambrano, J.R., Alarcón, G.W.H., Villeneuve, P., Pina, M., Nouy, B., Amblard, P., Ritter, E., Leroy, T. and Billotte, N. (2013) Quantitative Trait Loci (QTLs) Analysis of Palm Oil Fatty Acid Composition in an Interspecific Pseudo-Backcross from Elaeis oleifera (H.B.K.) Cortés and Oil Palm (Elaeis guineensis Jacq.). Tree Genetics and Genomes, 9, 1207-1225. https://doi.org/10.1007/s11295-013-0629-5

[4] Zhang, A., Wang, H., Beyene, Y., Semagn, K., Liu, Y., Cao, S., Cui, Z., Ruan, Y., Burgueño, J., San Vicente, F., Olsen, M., Prasanna, B.M., Crossa, J., Yu, H. and Zhang, X. (2017) Effect of Trait Heritability, Training Population Size and Marker 
Density on Genomic Prediction Accuracy Estimation in 22 Bi-Parental Tropical Maize Populations. Frontiers in Plant Science, 8, Article No. 1916. https://doi.org/10.3389/fpls.2017.01916

[5] Cros, D., Tchounke, B. and Nkague-Nkamba, L. (2018) Training Genomic Selection Models across Several Breeding Cycles Increases Genetic Gain in Oil Palm in Silico Study. Molecular Breeding, 38, Article No. 89. https://doi.org/10.1007/s11032-018-0850-x

[6] Wong, C.K. and Bernardo, R. (2008) Genomewide Selection in Oil Palm: Increasing Selection Gain per Unit Time and Cost with Small Populations. Theoretical and Applied Genetics, 116, 815-824. https://doi.org/10.1007/s00122-008-0715-5

[7] USDA (2020). https://www.fas.usda.gov/data/oilseeds-world-markets-and-trade

[8] Babu, B.K. and Mathur, R.K. (2016) Molecular Breeding in Oil Palm (Elaeis guineensis): Status and Future Perspectives. Progressive Horticulture, 48, 123-131. https://doi.org/10.5958/2249-5258.2016.00051.8

[9] Corley, R.H.V. and Tinker, P.B. (2016) The Oil Palm. Wiley-Blackwell, Hoboken. https://doi.org/10.1002/9781118953297

[10] Soh, A.C., Mayes, S. and Roberts, J.A. (2017) Oil Palm Breeding: Genetics and Genomics. 1st Edition, CRC Press, Boca Raton. https://doi.org/10.1201/9781315119724-1

[11] Kwong, Q.B., Teh, C.K., Ong, A.L., Heng, H.Y., Lee, H.L., Mohamed, M., Low, J.Z.B., Apparow, S., Chew, F.T., Mayes, S., Kulaveerasingam, H., Tammi, M. and Appleton, D.R. (2016) Development and Validation of a High-Density SNP Genotyping Array for African Oil Palm. Molecular Plant, 9, 1132-1141.

https://doi.org/10.1016/j.molp.2016.04.010

[12] Herrero, J., Santika, B., Herrán, A., Erika, P., Sarimana, U., Wendra, F., Sembiring, Z., Asmono, D. and Ritter, E. (2020) Construction of a High Density Linkage Map in Oil Palm Using SPET Markers. Scientific Reports, 10, Article No. 9998. https://doi.org/10.1038/s41598-020-67118-y

[13] Xu, Y. and Crouch, J.H. (2008) Marker-Assisted Selection in Plant Breeding: From Publications to Practice. Crop Science, 48, 391-407.

https://doi.org/10.2135/cropsci2007.04.0191

[14] Mayes, S., Jack, P.L., Corley, R.H. and Marshall, D.F. (1997) Construction of a RFLP Genetic Linkage Map for Oil Palm (Elaeis guineensis Jacq.). Genome, 40, 116-122. https://doi.org/10.1139/g97-016

[15] Lee, M., Xia, J.H., Zou, Z., Ye, J., Rahmadsyah, Alfiko, Y., Jin, J., Lieando, J.V., Purnamasari, M.I., Lim, C.H., Suwanto, A., Wong, L., Chua, N.H. and Yue, G.H. (2015) A Consensus Linkage Map of Oil Palm and a Major QTL for Stem Height. Scientific Reports, 5, Article No. 8232. https://doi.org/10.1038/srep08232

[16] O’Rourke, J.A. (2014) Genetic and Physical Map Correlation. eLS, Wiley-Blackwell, Hoboken, 1-4. https://doi.org/10.1002/9780470015902.a0000819.pub3

[17] Billotte, N., Marseillac, N., Risterucci, A.M., Adon, B., Brottier, P., Baurens, F.C., Singh, R., Herrán, A., Asmady, H., Billot, C., Amblard, P., Durand-Gasselin, T., Courtois, B., Asmono, D., Cheah, S.C., Rohde, W., Ritter, E. and Charrier, A. (2005) Microsatellite-Based High Density Linkage Map in Oil Palm (Elaeis guineensis Jacq.). Theoretical and Applied Genetics, 110, 754-765. https://doi.org/10.1007/s00122-004-1901-8

[18] Singh, R., Tan, S.G., Panandam, J.M., Rahman, R.A., Ooi, L.C., Low, E.T.L., Sharma, M., Jansen, J. and Cheah, S.C. (2009) Mapping Quantitative Trait Loci (QTLs) for 
Fatty Acid Composition in an Interspecific Cross of Oil Palm. BMC Plant Biology, 9, Article No. 114. https://doi.org/10.1186/1471-2229-9-114

[19] Moretzsohn, M.C., Nunes, C.D.M., Ferreira, M.E. and Grattapaglia, D. (2000) RAPD Linkage Mapping of the Shell Thickness Locus in Oil Palm (Elaeis guineensis Jacq.). Theoretical and Applied Genetics, 100, 63-70. https://doi.org/10.1007/s001220050009

[20] Billotte, N., Jourjon, M.F., Marseillac, N., Berger, A., Flori, A., Asmady, H., Adon, B., Singh, R., Nouy, B., Potier, F., Cheah, S.C., Rohde, W., Ritter, E., Courtois, B., Charrier, A. and Mangin, B. (2010) QTL Detection by Multi-Parent Linkage Mapping in Oil Palm (Elaeis guineensis Jacq.). Theoretical and Applied Genetics, 120, 1673-1687. https://doi.org/10.1007/s00122-010-1284-y

[21] Cochard, B., Carrasco-Lacombe, C., Pomies, V., Dufayard, J.F., Suryana, E., Omoré, A., Tristan, D.G. and Tisné, S. (2015) Pedigree-Based Linkage Map in Two Genetic Groups of Oil Palm. Tree Genetics and Genomes, 11, Article No. 68. https://doi.org/10.1007/s11295-015-0893-7

[22] Seng, T.Y., Saad, S.H.M., Chin, C.W., Ting, N.C., Singh, R.S.H., Zaman, F.Q., Tan, S.G. and Alwee, S.S.R.S. (2011) Genetic Linkage Map of a High Yielding FELDA Deli×Yangambi Oil Palm Cross. PLoS ONE, 6, e26593.

https://doi.org/10.1371/journal.pone.0026593

[23] Ukoskit, K., Chanroj, V., Bhusudsawang, G., Pipatchartlearnwong, K., Tangphatsornruang, S. and Tragoonrung, S. (2014) Oil Palm (Elaeis guineensis Jacq.) Linkage Map, and Quantitative Trait Locus Analysis for Sex Ratio and Related Traits. Molecular Breeding, 33, 415-424. https://doi.org/10.1007/s11032-013-9959-0

[24] Gan, S.T., Wong, W.C., Wong, C.K., Soh, A.C., Kilian, A., Low, E.T.L., Massawe, F. and Mayes, S. (2018) High Density SNP and DArT-Based Genetic Linkage Maps of Two Closely Related Oil Palm Populations. Journal of Applied Genetics, 59, 23-34. https://doi.org/10.1007/s13353-017-0420-7

[25] Ong, A.L., Teh, C.K., Kwong, Q.B., Tangaya, P., Appleton, D.R., Massawe, F. and Mayes, S. (2019) Linkage-Based Genome Assembly Improvement of oil Palm (Elaeis guineensis). Scientific Reports, 9, Article No. 6619. https://doi.org/10.1038/s41598-019-42989-y

[26] Ong, A.L., Teh, C.K., Mayes, S., Massawe, F., Appleton, D.R. and Kulaveerasingam, H. (2020) An Improved Oil Palm Genome Assembly as a Valuable Resource for Crop Improvement and Comparative Genomics in the Arecoideae Subfamily. Plants, 9, Article No. 1476. https://doi.org/10.3390/plants9111476

[27] Pootakham, W., Jomchai, N., Ruang-areerate, P., Shearman, J.R., Sonthirod, C., Sangsrakru, D., Tragoonrung, S. and Tangphatsornruang, S. (2015) Genome-Wide SNP Discovery and Identification of QTL Associated with Agronomic Traits in Oil Palm Using Genotyping-by-Sequencing (GBS). Genomics, 105, 288-295. https://doi.org/10.1016/j.ygeno.2015.02.002

[28] Bai, B., Zhang, Y.J., Wang, L., Lee, M., Rahmadsyah, Ye, B.Q., Alfiko, Y., Purwantomo, S., Suwanto, A. and Yue, G.H. (2018) Mapping QTL for Leaf Area in Oil Palm Using Genotyping by Sequencing. Tree Genetics and Genomes, 14, Article No. 31. https://doi.org/10.1007/s11295-018-1245-1

[29] Rance, K.A., Mayes, S., Price, Z., Jack, P.L. and Corley, R.H.V. (2001) Quantitative Trait Loci for Yield Components in Oil Palm (Elaeis guineensis Jacq.). Theoretical and Applied Genetics, 103, 1302-1310. https://doi.org/10.1007/s122-001-8204-Z

[30] Ting, N.C., Jansen, J., Nagappan, J., Ishak, Z., Chin, C.W., Tan, S.G., Cheah, S.C. and Singh, R. (2013) Identification of QTLs Associated with Callogenesis and Em- 
bryogenesis in Oil Palm Using Genetic Linkage Maps Improved with SSR Markers. PLOS ONE, 8, e53076. https://doi.org/10.1371/journal.pone.0053076

[31] Meksem, K., Ishihara, H. and Jesse, T. (2005) Integration of Physical and Genetic Maps. In: Meksem, K. and Kahl, G., Eds., The Handbook of Plant Genome Mapping. Genetic and Physical Mapping, Wiley-VCH Verlag GmbH \& Co. KGaA, Weinheim, 215-232. https://doi.org/10.1002/3527603514.ch9

[32] Meksem, K. and Kahl, G. (2005) The Handbook of Plant Genome Mapping: Genetic and Physical Mapping. 1st Edition, Wiley-VCH Verlag GmbH \& Co. KGaA, Weinheim. https://doi.org/10.1002/3527603514

[33] Dixit, R., Jayanand, D., Rai, D., Agarwal, R. and Pundhir, A. (2014) Physical Mapping of Genome and Genes. Journal of Biological Engineering Research and Review, 1, 6-11.

[34] Shah, M., Varshney, P., Patel, P., Patel, D. and Meshram, D. (2012) Cytogenetic Mapping Techniques: An Approach to Genome Analysis. Research \& Reviews in BioSciences, 7, 209-219.

[35] Hozier, J.C. and Davis, L.M. (1992) Cytogenetic Approaches to Genome Mapping. Analytical Biochemistry, 200, 205-217. https://doi.org/10.1016/0003-2697(92)90455-G

[36] Azhaguvel, P., Weng, Y., Babu, R., Manickavelu, A., Saraswathi, D. and Balyan, H. (2010) Fundamentals of Physical Mapping. In: Kole, C. and Abbott, A.G., Eds., Principles and Practices of Plant Genomics, CRC Press, Boca Raton, 24-62.

[37] Brown, T.A. (2002) Mapping Genomes, Genomes. 2nd Edition, Wiley-Liss, Hoboken.

[38] Deonier, R.C., Waterman, M.S. and Tavaré, S. (2005) Physical Mapping of DNA. Computational Genome Analysis. An Introduction. Springer, New York, 99-119. https://doi.org/10.1007/0-387-28807-4_4

[39] Hass-Jacobus, B. and Jackson, S.A. (2005) Physical Mapping of Plant Chromosomes. In: Meksem, K. and Kahl, G., Eds., The Handbook of Plant Genome Mapping, Wiley-VCH Verlag GmbH \& Co. KGaA, Weinheim, 131-149. https://doi.org/10.1002/3527603514.ch6

[40] Lewin, H.A., Larkin, D.M., Pontius, J. and O’Brien, S.J. (2009) Every Genome Sequence Needs a Good Map. Genome Research, 19, 1925-1928. https://doi.org/10.1101/gr.094557.109

[41] Griffiths, A.J., Miller, J.H., Suzuki, D.T., Lewontin, R.C. and Gelbart, W.M. (2000) An Introduction to Genetic Analysis. 7th Edition, W.H. Freeman, New York.

[42] Li, Y. (2015) Construction of a High-Density High-Resolution Genetic Map and Its Integration with BAC-Based Physical Map in Channel Catfish. DNA Research, 22, 39-52. https://doi.org/10.1093/dnares/dsu038

[43] Sturtevant, A.H. (1913) The Linear Arrangement of Six Sex-Linked Factors in Drosophila, as Shown by Their Mode of Association. Journal of Experimental Zoology, 14, 43-59. https://doi.org/10.1002/jez.1400140104

[44] Alves, J.M., Chikhi, L., Amorim, A. and Lopes, A.M. (2014) The 8p23 Inversion Polymorphism Determines Local Recombination Heterogeneity across Human Populations. Genome Biology and Evolution, 6, 921-930. https://doi.org/10.1093/gbe/evu064

[45] Botstein, D., White, R.L., Skolnick, M. and Davis, R.W. (1980) Construction of a Genetic Linkage Map in Man Using Restriction Fragment Length Polymorphisms. American Journal of Human Genetics, 32, 314-331.

[46] Williams, J.G., Kubelik, A.R., Livak, K.J., Rafalski, J.A. and Tingey, S.V. (1990) DNA 
Polymorphisms Amplified by Arbitrary Primers Are Useful as Genetic Markers. Nucleic Acids Research, 18, 6531-6535. https://doi.org/10.1093/nar/18.22.6531

[47] Litt, M. and Luty, J.A. (1989) A Hypervariable Microsatellite Revealed by in Vitro Amplification of a Dinucleotide Repeat within the Cardiac Muscle Actin Gene. American Journal of Human Genetics, 44, 397-401.

[48] Palazzolo, M.J., Sawyer, S.A., Martin, C.H., Smoller, D.A. and Hartl, D.L. (1991) Optimized Strategies for Sequence-Tagged-Site Selection in Genome Mapping. Proceedings of the National Academy of Sciences of the United States of America, 88, 8034-8038. https://doi.org/10.1073/pnas.88.18.8034

[49] Vos, P., Hogers, R., Bleeker, M., Reijans, M., van de Lee, T., Hornes, M., Frijters, A., Pot, J., Peleman, J. and Kuiper, M. (1995) AFLP: A New Technique for DNA Fingerprinting. Nucleic Acids Research, 23, 4407-4414. https://doi.org/10.1093/nar/23.21.4407

[50] Lai, E., Riley, J., Purvis, I. and Roses, A. (1998) A 4-Mb High-Density Single Nucleotide Polymorphism-Based Map around Human APOE. Genomics, 54, 31-38. https://doi.org/10.1006/geno.1998.5581

[51] Williams, M.N.V., Pande, N., Nair, S., Mohan, M. and Bennett, J. (1991) Restriction Fragment Length Polymorphism Analysis of Polymerase Chain Reaction Products Amplified from Mapped Loci of Rice (Oryza sativa L.) Genomic DNA. Theoretical and Applied Genetics, 82, 489-498. https://doi.org/10.1007/BF00588604

[52] Lyamichev, V., Brow, M.A. and Dahlberg, J.E. (1993) Structure-Specific Endonucleolytic Cleavage of Nucleic Acids by Eubacterial DNA Polymerases. Science, 260, 778-783. https://doi.org/10.1126/science.7683443

[53] Bai, B., Wang, L., Zhang, Y.J., Lee, M., Rahmadsyah, R., Alfiko, Y., Ye, B.Q., Purwantomo, S., Suwanto, A., Chua, N.H. and Yue, G.H. (2018) Developing Genome-Wide SNPs and Constructing an Ultrahigh-Density Linkage Map in Oil Palm. Scientific Reports, 8, Article No. 691. https://doi.org/10.1038/s41598-017-18613-2

[54] Jeennor, S. and Volkaert, H. (2014) Mapping of Quantitative Trait Loci (QTLs) for Oil Yield Using SSRs and Gene-Based Markers in African Oil Palm (Elaeis guineensis Jacq.). Tree Genetics and Genomes, 10, 1-14.

https://doi.org/10.1007/s11295-013-0655-3

[55] Ting, N.C., Jansen, J., Mayes, S., Massawe, F., Sambanthamurthi, R., Ooi, L.C.L., Chin, C.W., Arulandoo, X., Seng, T.Y., Alwee, S.S.R.S., Ithnin, M. and Singh, R. (2014) High Density SNP and SSR-Based Genetic Maps of Two Independent Oil Palm Hybrids. BMC Genomics, 15, Article No. 309.

https://doi.org/10.1186/1471-2164-15-309

[56] Xia, W., Luo, T., Zhang, W., Mason, A.S., Huang, D., Huang, X., Tang, W., Dou, Y., Zhang, C. and Xiao, Y. (2019) Development of High-Density SNP Markers and Their Application in Evaluating Genetic Diversity and Population Structure in Elaeis guineensis. Frontiers in Plant Science, 10, Article No. 130.

https://doi.org/10.3389/fpls.2019.00130

[57] Rastas, P. (2017) Lep-MAP3: Robust Linkage Mapping Even for Low-Coverage Whole Genome Sequencing Data. Bioinformatics, 33, 3726-3732.

https://doi.org/10.1093/bioinformatics/btx494

[58] Lander, E.S., Green, P., Abrahamson, J., Barlow, A., Daly, M.J., Lincoln, S.E. and Newburg, L. (1987) MAPMAKER: An Interactive Computer Package for Constructing Primary Genetic Linkage Maps of Experimental and Natural Populations. Genomics, 1, 174-181.

[59] Stam, P. (1993) Construction of Integrated Genetic Linkage Maps by Means of a 
New Computer Package: Join Map. The Plant Journal, 3, 739-744.

[60] Ooijen, J.W. and Voorrips, R.E. (2002) JoinMap: Version 3.0: Software for the Calculation of Genetic Linkage Maps. University and Research Center.

[61] Van Ooijen, J.W. (2006) JoinMap ${ }^{\star} 4$, Software for the Calculation of Genetic Linkage Maps in Experimental Populations. Kyazma B.V., Wagening.

[62] Rastas, P., Paulin, L., Hanski, I., Lehtonen, R. and Auvinen, P. (2013) Lep-MAP: Fast and Accurate Linkage Map Construction for Large SNP Datasets. Bioinformatics, 29, 3128-3134. https://doi.org/10.1093/bioinformatics/btt563 